\title{
APLICAÇÃO DE SONDAGEM ELÉTRICA VERTICAL NA ESTIMATIVA DO TOPO E DA ESPESSURA DE UNIDADES GEOLÓGICAS DA BACIA DO PARANÁ NA CIDADE DE RONDONÓPOLIS-MT
}

\author{
Alterêdo Oliveira Cutrim e Aldo da Cunha Rebouças² \\ Recebido em 4 maio, 2005 / Aceito em 20 julho, 2005 \\ Received on May 4, 2005 / Accepted on July 20, 2005
}

\begin{abstract}
The research was carried out in Rondonopolis city, Mato Grosso State, Brazil, to estimate the depth and thickness of geological formations occurring in the area, using vertical electrical sounding (VES). The results show that the maximum thickness of Ponta Grossa Formation is $63 \mathrm{~m}$, and that the joint thickness of Furnas/Ponta Grossa transition and the Furnas Formation is greater to $700 \mathrm{~m}$. The thickness of Furnas/Ponta Grossa transition could not be estimated due to lack of evidence in VES curves. It was observed a considerable litological variation in Furnas Formation. Geological data from wells used in the interpretation of VES allows greater reliability for the obtained results.
\end{abstract}

Keywords: VES, Paraná Basin, hydrogeology, Rondonópolis-MT.

RESUMO. Este estudo foi realizado na cidade de Rondonópolis, estado de Mato Grosso, e teve como objetivo estimar a profundidade e a espessura das unidades geológicas da área, usando Sondagem Elétrica Vertical (SEV). Os resultados das SEVs mostram que a espessura máxima da Formação Ponta Grossa é 63 m; a espessura da transição Furnas/Ponta Grossa e da Formação Furnas é superior a 700 m. A espessura da mencionada transição não foi estimada por falta de evidências nas curvas das SEVs. Foi observada uma variação litológica considerável na Formação Furnas. Os dados de perfis geológicos de poços, usados na interpretação das SEVs, permitiram maior confiabilidade nos resultados obtidos.

Palavras-chave: SEV, Bacia do Paraná, hidrogeologia, Rondonópolis-MT.

\footnotetext{
${ }_{1}^{1}$ Professor do Departamento Geologia Geral, Universidade Federal de Mato Grosso - UFMT, Instituto de Ciências Exatas e da Terra - ICET. Av. Fernando Correa da Costa, S/N-Coxipó, 78060-900 Cuiabá, MT, Brasil. Fone: (65) 615-8751; Fax: (65) 615-8752 - E-mail- alteredo@cpd.ufmt.br

2 Professor colaborador da Pós-Graduação em Geociências - IGc. Instituto de Geociências - IGc, Universidade de São Paulo, Rua do Lago, 562 - Cidade Universitária, 05508-900 São Paulo, SP, Brasil. Fone: (11) 3091-4143 - E-mail: aldoreb@osite.com.br
} 


\section{INTRODUÇ̃̃̃O}

0 conhecimento da profundidade e espessura de unidades geológicas é de grande importância para estudos hidrogeológicos envolvendo prospecção, quantificação, vulnerabilidade e elaboração de modelo hidrogeológico conceitual, além de auxiliar na elaboração de projeto de poço tubular profundo. Essas informações na prospecção de água subterrânea indicam 0 local mais adequado para construir o poço e a profundidade mais provável do(s) aqüifero(s), dados importantes na elaboração de projeto de poço tubular. Na quantificação de reservas de aqüífero a espessura é um parâmetro extremamente importante, pois o seu volume de água é diretamente proporcional à sua espessura (Cutrim \& Rebouças, 2005; Rebouças, 1976; Costa, 2000). A profundidade do aqüífero e a espessura das unidades que 0 confinam são parâmetros de grande influência no grau de vulnerabilidade à contaminação de um aqǘf́ero confinado (Foster et al., 2002; Cutrim \& Rebouças, inédito a). Na formulação de modelo hidrogeológico conceitual essas informações compõe a dimensão vertical do modelo (Anderson \& Woessner, 1992).

A espessura e profundidade das unidades geológicas podem ser obtidas de modo direto através de perfis geológicos de poços tubulares e de modo indireto por meio de métodos geofísicos, cuja aplicação depende da geologia local. Os perfis geológicos dos poços tubulares, nem sempre apresentam essas informações com 0 grau de precisão exigido para tais estudos hidrogeológicos. Além disso, normalmente os poços têm uma distribuição muito irregular e a profundidade raramente atravessa toda a espessura do aqǘfero explorado.

Desse modo, os métodos geofísicos podem ser aplicados com o objetivo de complementar informações fornecidas por perfis de poços ou de produzir dados onde inexistam poços. No entanto, o grau de precisão dos resultados produzidos pela geofísica está diretamente vinculado ao conhecimento geológico da área, devido ao problema da ambigüidade dos métodos geofísicos.

Como os métodos geofísicos são aplicados de acordo com a geologia de cada local, e a área de estudo está inserida na Bacia do Paraná, então foi aplicado o método da sondagem elétrica vertical (SEV), pela sua conhecida eficiência na produção de tais informações (Cutrim et al., 2001; Cutrim et al., 2002; Cutrim \& Fachin, 2004).

Embora na área existe um grande número de poços tubulares, eles estão heterogeneamente distribuídos e nenhum atravessou toda a espessura do principal aqüifero (a Formação Furnas). Como a grande maioria dos dados de perfil geológico não são confiáveis, a aplicação de SEV foi integrada com as informações geológicas mais confiáveis de apenas três poços (Figuras 4 e 5). Este procedimento garantiu maior confiabilidade na estimativa da profundidade ao topo e da espessura das unidades geológicas.

\section{CARACTERÍSTICAS DA ÁREA DE ESTUDO Aspectos Gerais}

A área de estudo compreende a cidade de Rondonópolis e 0 seu entorno, e está localizada no sudeste do estado de Mato Grosso entre os paralelos $16^{\circ} 25^{\prime} \mathrm{S}$ e $16^{\circ} 30^{\prime} \mathrm{S}$ e os meridianos $54^{\circ} 40^{\prime} 20^{\prime \prime} \mathrm{W}$ e $54^{\circ} 34^{\prime} 50^{\prime \prime} \mathrm{W}$ (Figura 1). Ela está localizada na bacia hidrográfica do rio Vermelho, afluente do rio São Lourenço, ambos inseridos nos domínios do Pantanal Mato-Grossense. Essa cidade possui uma população em torno de 140.000 habitantes e é o terceiro mais importante núcleo urbano do estado. Nela a água subterrânea supre $53 \%$ da demanda do abastecimento público, 60\% da necessidade do comércio, 100\% da demanda da indústria, lazer, hospitais e irrigação de pequenos pomares e 10\% de residências através de poços individuais (Cutrim \& Rebouças, inédito b).

\section{Geologia da Área}

A geologia da área, segundo Ruiz et al. (inédito), é composta por rochas devonianas da Formação Furnas, da zona de transição Furnas/Ponta Grossa e da Formação Ponta Grossa, pertencentes ao flanco noroeste da Bacia do Paraná e por depósitos aluvionares (Figura 2).

A Formação Furnas é composta por um espesso pacote de arenitos médios a grossos, sendo que em direção ao topo predominam psamo-pelíticos, constituindo bancos de areia fina micácea intercalados por lâminas decimétricas de argilas e siltes. Os arenitos quartzosos são mais abundantes e apresentam variações feldspáticas, com impregnações de óxido de ferro, grau médio de seleção, grãos esféricos e coloração variando de cinza esbranquiçado a rósea. Na área esta unidade aflora, principalmente, no sudoeste e parte central, com ocorrência de falhamentos de direção preferencial sudoeste/nordeste. 0 seu contato com a transição Furnas/Ponta Grossa é concordante, ou por falhamentos de gravidade.

A zona de transição Furnas/Ponta Grossa atinge espessuras entre $10 \mathrm{~m}$ e 40 m e é caracterizada pela interdigitação de finas camadas de arenitos de textura fina a muito fina, siltitos e folhelhos sílticos com bastante mica.

A Formação Ponta Grossa, segundo aqueles autores, é constituída pelas fases pelítica e psamo-pelítica. A fase pelítica ocorre nas porções noroeste, nordeste e sudeste, e é composta por folhe- 


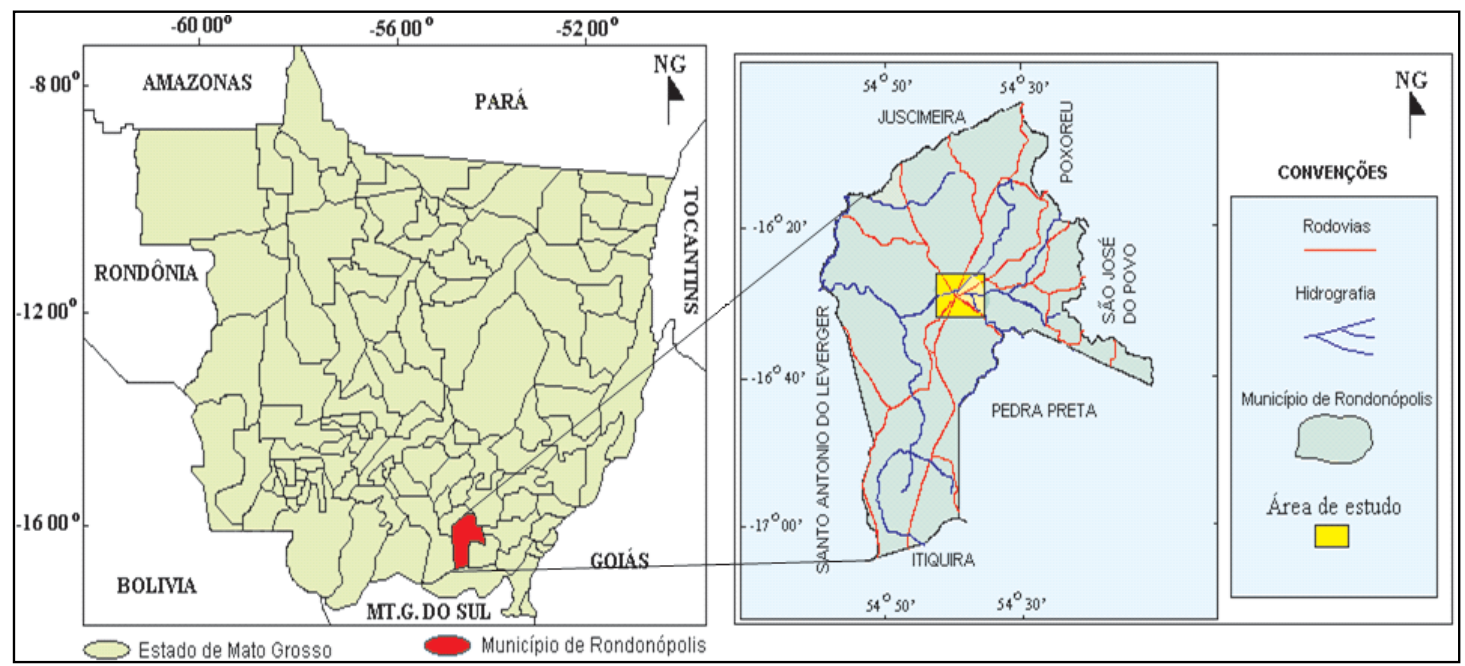

Figura 1 - Localização da área de estudo.

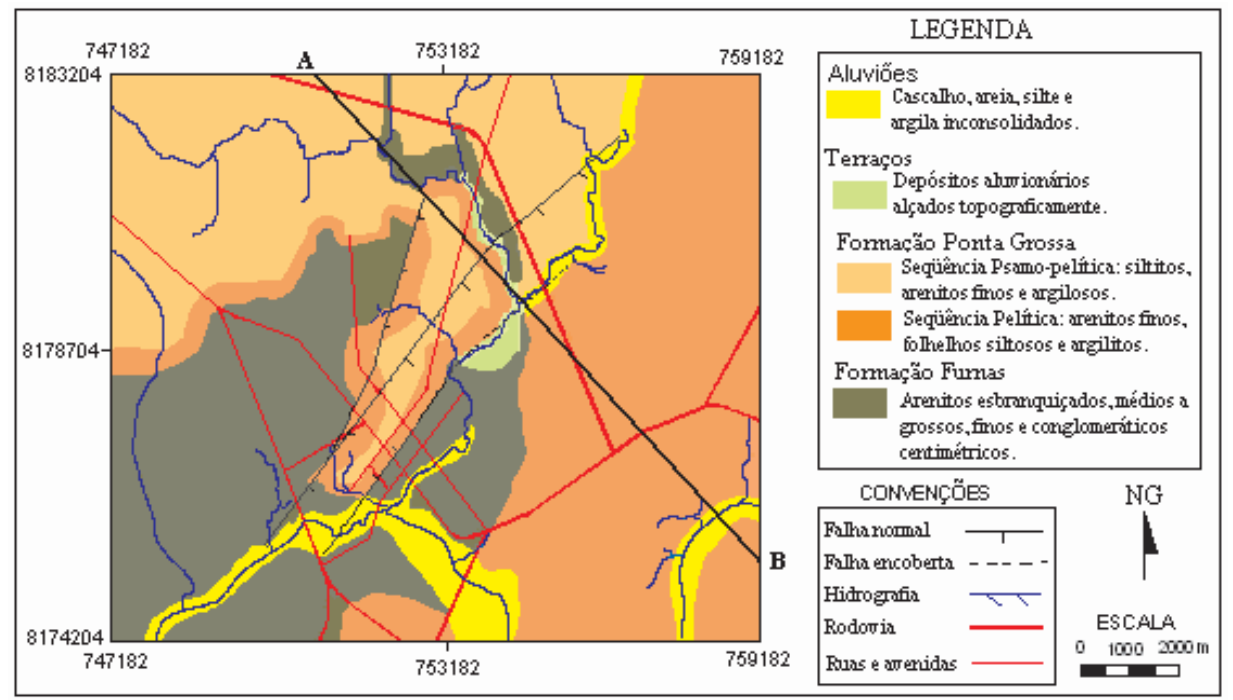

Figura 2 - Mapa geológico da área (Modificado de Ruiz et al., inédito).

Ihos sílticos, com intercalações de argilitos, e em direção ao topo ocorrem siltitos e arenitos muito finos, sendo comum a presença de fósseis nos arenitos e siltitos, indicando, assim, corresponder à parte de topo da formação. A fase psamo-pelítica ocorre em parte do centro da área, sendo constituída por siltitos e arenitos finos a muito finos e argilitos subordinados, caracterizando a porção intermediária à basal da formação. Esta unidade encontrase sobreposta à zona de transição Furnas/Ponta Grossa e o seu contato é gradacional e concordante ou por falhamentos de gravidade.

Os depósitos aluvionares, de idade quaternária, são constituídos por sedimentos areno-argilosos e cascalhos subordina- dos. A sua ocorrência se dá ao longo do rio Vermelho e dos córregos Macaco e Arareau.

\section{Hidrogeologia da Área}

Segundo Cutrim \& Rebouças (inédito c), a hidrogeologia da área é constituída pelo Aquiclude Ponta Grossa e pelos Aqüíferos Furnas e transição Furnas/ Ponta Grossa. 0 Aqüífero Furnas é o principal reservatório de água subterrânea, com poços produzindo vazões que variam de 15 a $250 \mathrm{~m}^{3} / \mathrm{h}$, com capacidade específica oscilando de 03, a $28 \mathrm{~m}^{3} / \mathrm{h} / \mathrm{m}$. No Aqüífero transição Furnas/ Ponta Grossa os poços produzem vazões entre 3 e $14 \mathrm{~m}^{3} / \mathrm{h}$, com capacidade específica entre 0,1 e 0,29 $\mathrm{m}^{3} / \mathrm{h} / \mathrm{m}$. 0 Aquclude Ponta 
Grossa não pode ser explorado para fins de produção de água, pois os poços nesse meio produzem vazões em 2 e $2,5 \mathrm{~m}^{3} / \mathrm{h}$, com capacidade específica de 0,05 a $0,07 \mathrm{~m}^{3} / \mathrm{h} / \mathrm{m}$.

\section{MÉTODOS}

Neste trabalho foi aplicado o método da sondagem elétrica vertical (SEV), o qual consiste em injetar corrente elétrica no solo através de dois eletrodos ( $\mathrm{e}$ B $\mathrm{B}$, e medir a diferença de potencial entre outros dois eletrodos ( $M$ e N), localizados, normalmente, entre os eletrodos de corrente, segundo 0 arranjo Schlumberger (Figura 3).

A resistividade aparente é obtida a partir da diferença de potencial $(\Delta V)$, da corrente elétrica $(I)$ e do fator geométrico $(K)$, através da equação apresentada em Bhattacharya \& Patra (1968):

$$
\rho_{a}=\left(\frac{\Delta V}{I}\right) \cdot k
$$

em que

$\rho_{a}=$ resistividade aparente (0hm.m)

$\Delta v=$ diferença de potencial (mVolt)

$I=$ corrente elétrica $(\mathrm{mA})$

$$
k=\frac{2 \pi}{\frac{1}{A M}-\frac{1}{B M}-\frac{1}{A N}+\frac{1}{B N}}
$$

AM = distância (m) entre os eletrodos A e M

$\mathrm{AN}=$ distância (m) entre os eletrodos $\mathrm{A}$ e N

$B M=$ distância (m) entre os eletrodos B e M

$\mathrm{BN}=$ distância (m) entre os eletrodos B e N

Na coleta dos dados foi utilizado o arranjo Schlumberger (Figura 3), cuja resistividade aparente é dada por:

$$
\rho_{a}=\pi \cdot\left(\frac{a^{2}-b^{2}}{2 \cdot b}\right) \cdot \frac{\Delta V}{I}
$$

onde, $A B / 2=a$ e $M N / 2=b$.

Como a corrente flui de modo radial, então quanto maior a distância entre os pontos de injeção de corrente, maior será a profundidade investigada.

0 equipamento usado para coletar os dados foi um resistivímetro, com potência máxima de $250 \mathrm{~W}$ e voltagens de $100 \mathrm{~V}$, 200V, 400V e 800V. A resistência de contato nos eletrodos foi minimizada através do uso de água salgada. Ao todo foram realizadas 7 SEVs, em locais não pavimentados, no entorno da cidade (Figura 4), com abertura máxima de $A B / 2$ de $2 \mathrm{~km}$ e a distância de $M N \leq A B / 5$.
As SEVs foram interpretadas através do método Ridge Regression (Tikhonov \& Arsenin, 1977). No processo de interpretação, a espessura das unidades geológicas apresentada nos perfis dos poços tubulares 1,2 e 3 , localizados próximos às SEVs 3, 4 e 6 (Figura 5) foi utilizada para auxiliar na identificação dessas unidades nas curvas das SEVs e para estabelecer a relação $A B / 2$ / espessura da unidade geológica, a qual foi adotada para estimar a espessura dessas unidades, no processo de determinação do modelo interpretativa das SEVs.

\section{RESULTADOS E DISCUSSÕES}

Foram realizadas sete SEVs, cujos resultados estão apresentados nas Figuras 6 a 12 e na Tabela 1.

A SEV1 com abertura máxima de $A B / 2$ de $2000 \mathrm{~m}$ foi interpretada usando um modelo de sete camadas (Figura 6). As três primeiras camadas, com espessura em torno de 4,5 m, correspondem à cobertura pedológica. Essa variação de resistividade sugere heterogeneidade dos materiais desse meio. A quarta e a quinta camadas, com $40 \mathrm{~m}$ de espessura e profundidade ao topo de 4,5 m, correspondem à Formação Ponta Grossa, sobreposta à transição Furnas/Ponta Grossa. A sexta e a sétima camadas podem ser atribuídas à transição Furnas/Pontas Grossa conjuntamente com a Formação Furnas, com a profundidade ao topo e espessura estimadas em $45 \mathrm{~m}$ ( $A B / 2$ em torno de $120 \mathrm{~m}) \mathrm{e}$ maior que $400 \mathrm{~m}$ respectivamente.

A SEV2 com abertura máxima de $A B / 2$ de $2000 \mathrm{~m}$ foi interpretada usando um modelo de oito camadas (Figura 7). As três primeiras camadas referem-se à cobertura pedológica, cuja espessura total foi estimada em torno de 4 metros. Essa variação de resistividade sugere caráter heterogêneo para o meio pedológico. A quarta e a quinta camadas correspondem à Formação Ponta Grossa, cuja espessura é em torno de $63 \mathrm{~m}$ e a profundidade ao topo é 4 metros. A sexta, sétima e oitava camadas, totalizando uma espessura superior a $550 \mathrm{~m}$, representam a transição Furnas/Ponta Grossa e a Formação Furnas, com 66 m ( $A B$ /2 em torno de $180 \mathrm{~m}$ ) de profundidade ao topo da transição Furnas/Ponta Grossa.

A SEV3 com abertura máxima de $A B / 2$ de $700 \mathrm{~m}$ foi modelada através de um meio de quatro camadas (Figura 8). As camadas dois e três correspondem à cobertura pedológica, cuja espessura foi estimada em torno de 3 metros. A variação de resistividade sugere diferenças no material pedológico. A camada três refere-se à Formação Ponta Grossa, com espessura de aproximadamente $21 \mathrm{~m}$ e profundidade ao topo de 3 metros. A camada quatro com profundidade do topo de $24 \mathrm{~m}(\mathrm{AB} / 2$ de $60 \mathrm{~m}$ ) 


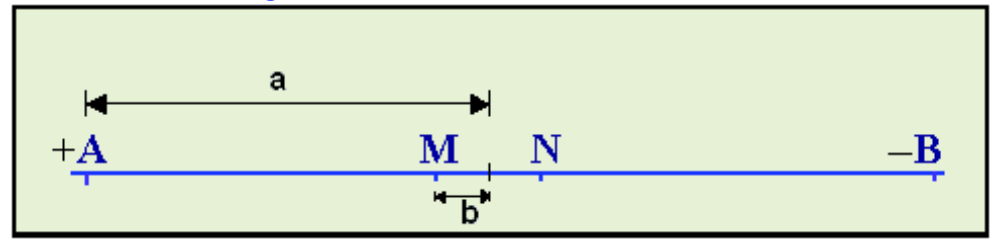

Figura 3 - Arranjo Schlumberger.

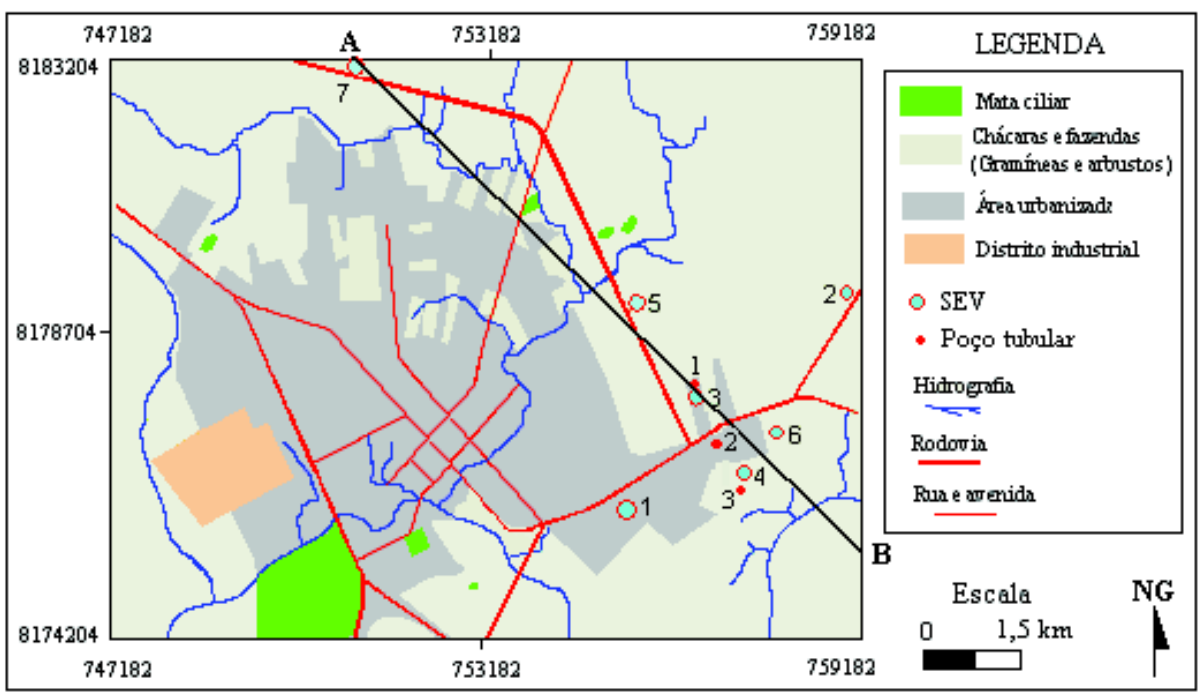

Figura 4 - Mapa de localização das sondagens elétricas verticais (SEVs) executadas e poços tubualres.
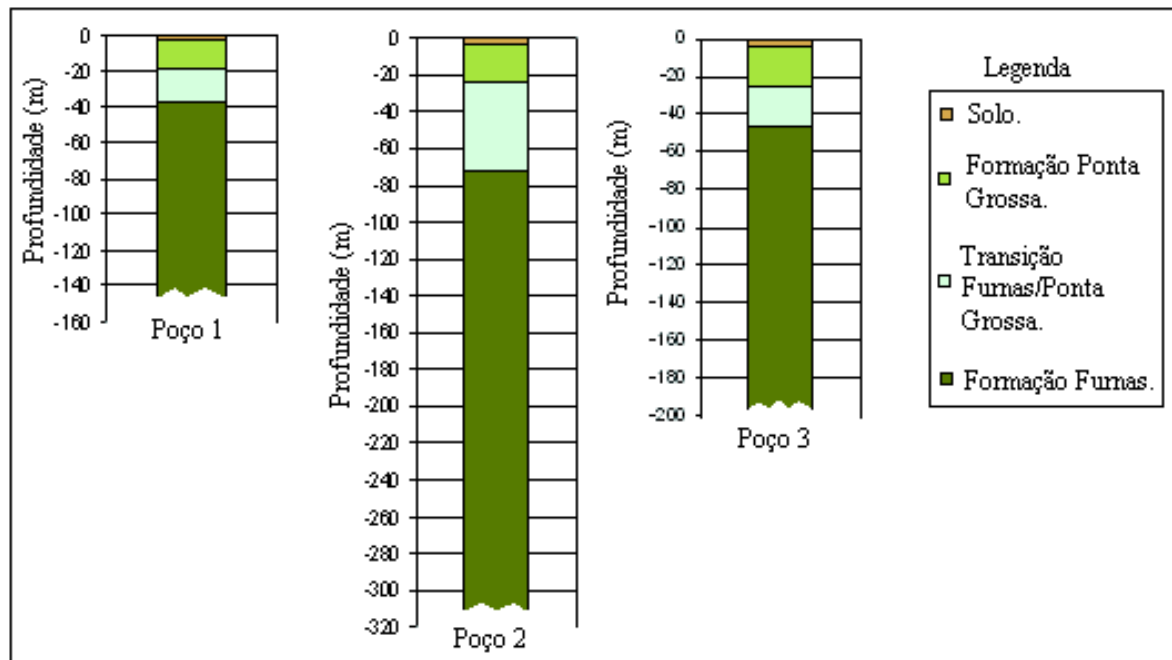

Poço 3

Figura 5 - Perfil geológico dos poços tubulares utilizados na interpretação das SEVs.

corresponde à transiçãa Furnas/Ponta Grossa e à Formação Furnas, cuja espessura total foi estimada superior a $250 \mathrm{~m}$, usando a aproximação $25 \%$ do AB máximo.

A SEV4 com abertura máxima de $A B / 2$ de 1500 m foi inter- pretada assumindo um modelo de seis camadas (Figura 9). As duas primeiras camadas, com espessura total de $3 \mathrm{~m}$, correspondem à cobertura pedológica, onde a diferença de resistividade sugere heterogeneidade do material pedológico. A terceira camada 


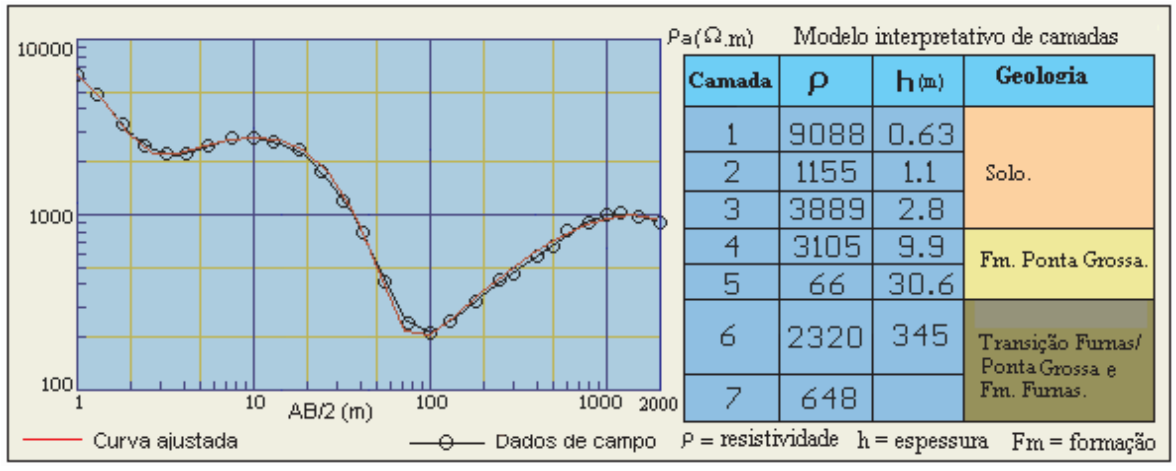

Figura 6 - Perfil geoelétrico da SEV1 e modelo interpretativo.

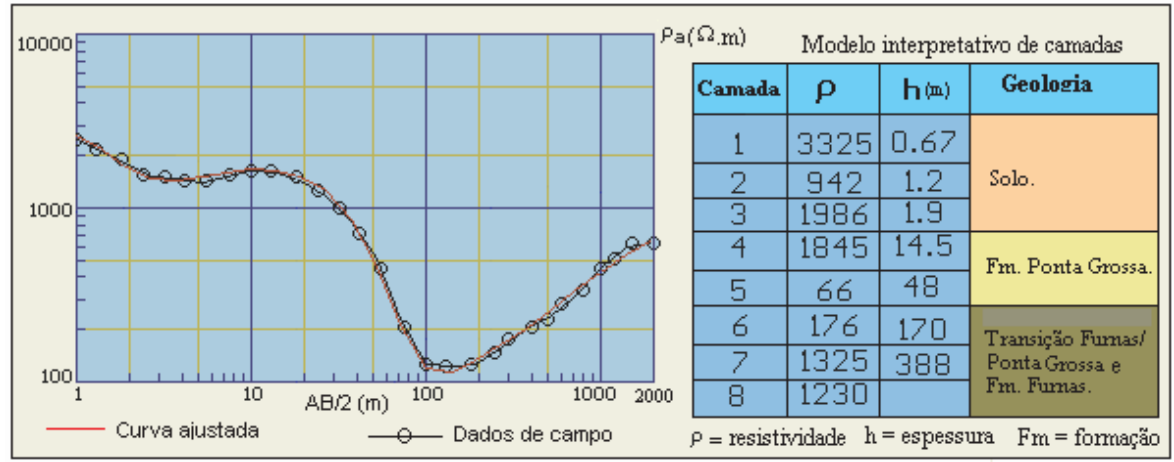

Figura 7 - Perfil geoelétrico da SEV2 e modelo interpretativo.

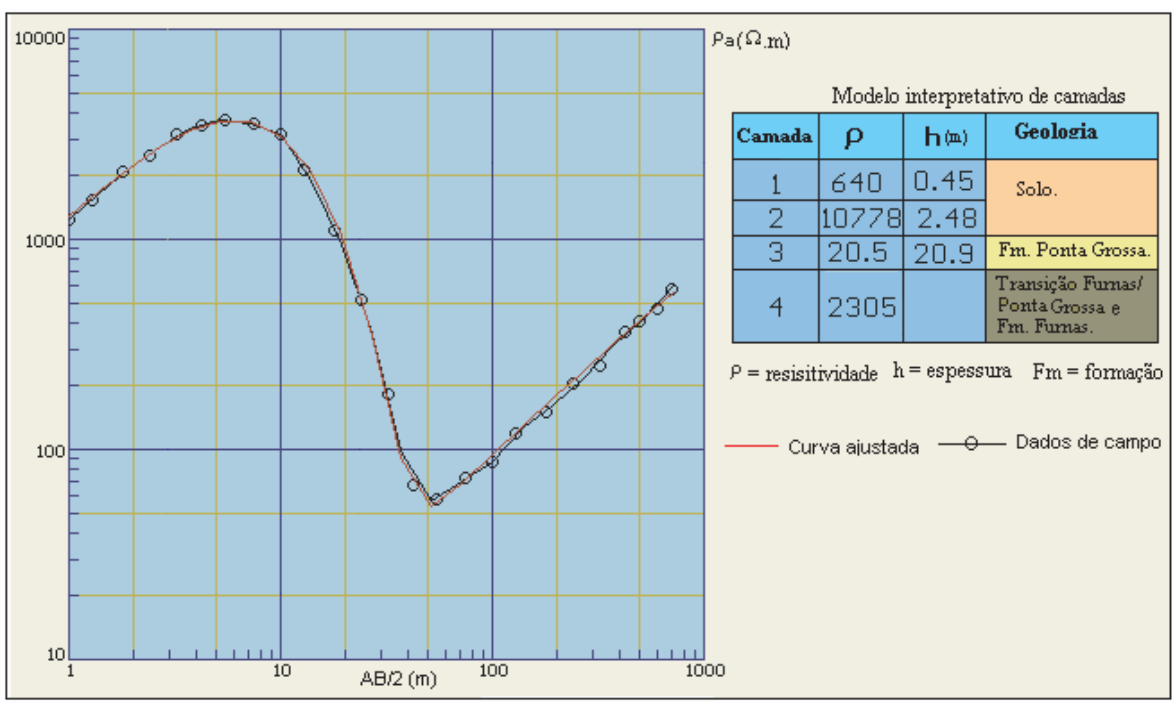

Figura 8 - Perfil geoelétrico da SEV3 e modelo interpretativo.

refere-se à Formação Ponta Grossa, cuja espessura e profundidade ao topo foram estimadas em $14 \mathrm{~m}$ e $3 \mathrm{~m}$, respectivamente. As camadas quatro, cinco e seis correspondem à transição Fur-
nas/Ponta Grossa e à Formação Furnas, com espessura superior a $300 \mathrm{~m}$ e profundidade ao topo estimada em $17 \mathrm{~m}$ ( $A B / 2$ de $50 \mathrm{~m}$ ). A variação de resistividade pode significar variação li- 


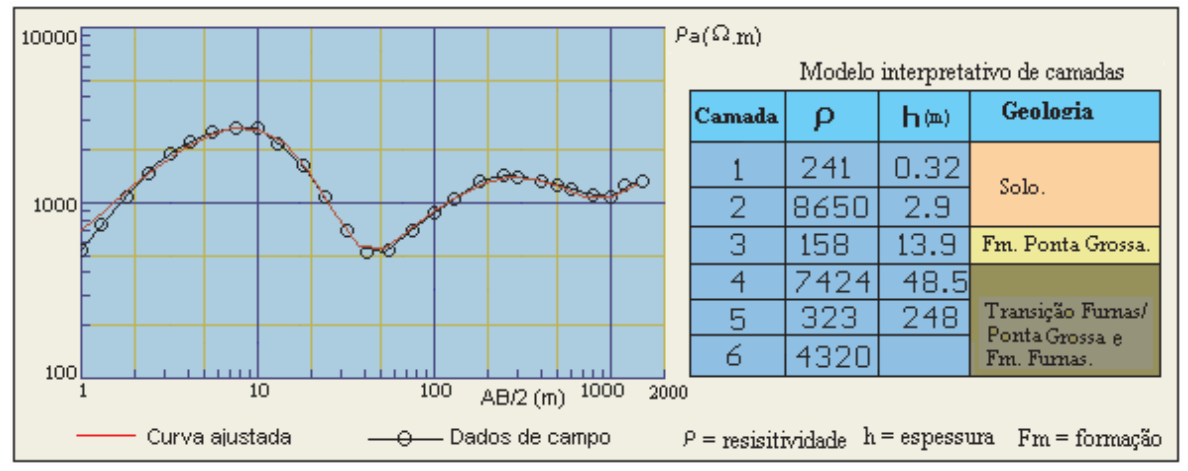

Figura 9 - Perfil geoelétrico da SEV4 e modelo interpretativo.

tológica dessas unidades.

A SEV5 com abertura máxima de $A B / 2$ de 2000 m foi modelada usando um meio de seis camadas (Figura 10). As duas primeiras camadas, com espessura estimada em torno de $3 \mathrm{~m}$, correspondem à cobertura pedológica, onde as diaerentes resistividades sugerem variações de material pedológico. A terceira e a quarta camadas, com espessura estimada em torno de $32 \mathrm{~m}$, representam a Formação Ponta Grossa, cuja profundidade ao topo é de aproximadamente 3 metros. A quinta e a sexta camadas, totalizando uma espessura superior a $700 \mathrm{~m}$, correspondem à transição Furnas/Ponta Grossa e à Formaç̧ão Furnas, cuja profundidade ao topo foi estimada em torno de $35 \mathrm{~m}(A B / 2$ de $80 \mathrm{~m})$.

A SEV6 com abertura máxima de $A B / 2$ de $1800 \mathrm{~m}$ foi interpretada adotando-se um modelo de seis camadas (Figura 11). As camadas um e dois, com espessura total de $3 \mathrm{~m}$, correspondem à cobertura pedológica, onde a variação de resistividade sugere variação pedológica desse meio. A camada três refere-se à Formação Ponta Grossa, cuja espessura e profundidade ao topo foram estimadas em $10 \mathrm{~m}$ e $3 \mathrm{~m}$, respectivamente. As camadas quatro, cinco e seis correspondem à transição Furnas/Ponta Grossa e à Formação Furnas, cuja profundidade ao topo e espessura foram estimadas em torno de $13 \mathrm{~m}(A B / 2$ de $30 \mathrm{~m}) \mathrm{e}$ superior a 700 metros. A variação de resistividade pode significar variação litológica dessas formações.

A SEV7 com abertura máxima de $A B / 2$ de 2000 m foi modelada através um meio de cinco camadas (Figura 12). As camadas um e dois, com espessura total de aproximadamente $3 \mathrm{~m}$, correspondem à cobertura pedológica, onde a variação de resistividade sugere uma variação pedológica do meio. As camadas três e quatro, com espessura total de $39 \mathrm{~m}$, referem-se à Formação Ponta Grossa, cuja profundidade ao topo está em torno de 3 metros. A camada cinco corresponde à transição Furnas/Ponta Grossa e à Formação Furnas, cuja profundidade ao topo é de $39 \mathrm{~m}(A B / 2$ em torno de 80 m) e a espessura superior a 700 metros. A variação de resistividade pode significar variaçãa litológica dessas unidades.

Ressalta-se que em nenhuma das SEVs foi possível identificar a base da transição Furnas/Ponta Grossa e 0 topo da Formação Furnas devido a suave gradação textural da primeira unidade para a segunda.

A Tabela 1 mostra que, em geral, a cobertura pedológica apresenta uma espessura variando entre $3 \mathrm{~m} \mathrm{e} 5 \mathrm{~m}$, a Formação Ponta Grossa tem espessura máxima de 63 m e a transição Furnas/Ponta Grossa conjuntamente com a Formação Furnas apresenta espessura superior 700 metros.

A Figura 13 mostra o perfil geológico A-B, de direção NWSE, elaborado a partir das SEVs 3, 4, 5 e 7, do mapa geológico e das espessuras das unidades geológicas apresentadas nos perfis dos poços tubulares 1,2 e 3 , distribuídos na vizinhança desse alinhamento. Observa-se nessa figura e na Tabela 1 que a espessura máxima da Formação Ponta Grossa é 63 m a nordeste, e que a espessura conjunta da transição Furnas/Ponta Grossa e Formação Furnas pode ser superior a 700 metros.

\section{CONCLUSÃO E CONSIDERAÇÕES}

Os resultados mostram que a espessura máxima da Formação Ponta Grossa é $63 \mathrm{~m}$, ocorrendo na parte nordeste da área.

A espessura da transição Furnas/Ponta Grossa não foi estimada devido a falta de evidência dessa unidade nas SEVs, ocasionada pela similaridade litológica dessa unidade com o topo da Formação Furnas. Em decorrência, foi considerada a espessura conjunta dessas unidades, a qual não foi estimada em virtude da abertura máxima de AB/2 das SEVs não ser suficiente para atingir a base da Formaç̧ão Furnas. No entanto, a partir dos maiores valores de $\mathrm{AB} / 2$ correspondentes a essas duas unidades, supõe-se que a espessura seja superior a 700 metros. 


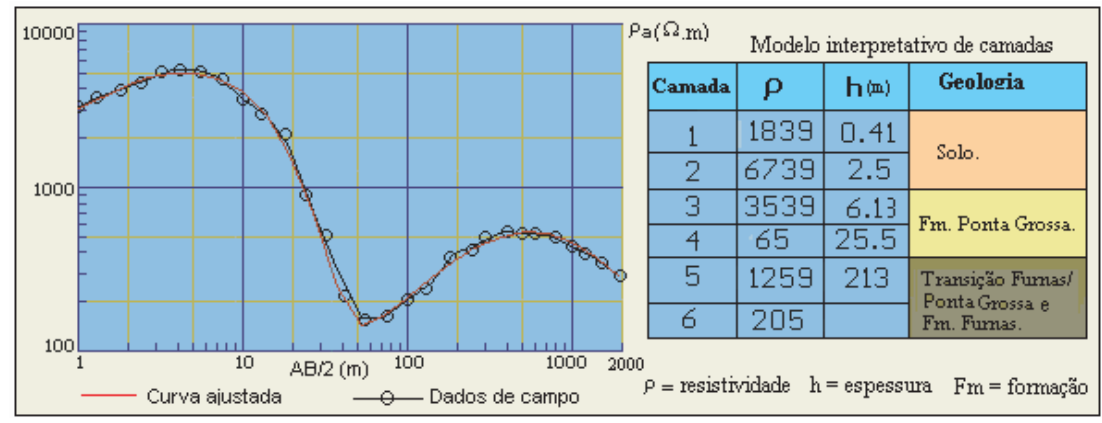

Figura 10 - Perfil geoelétrico da SEV5 e modelo interpretativo.

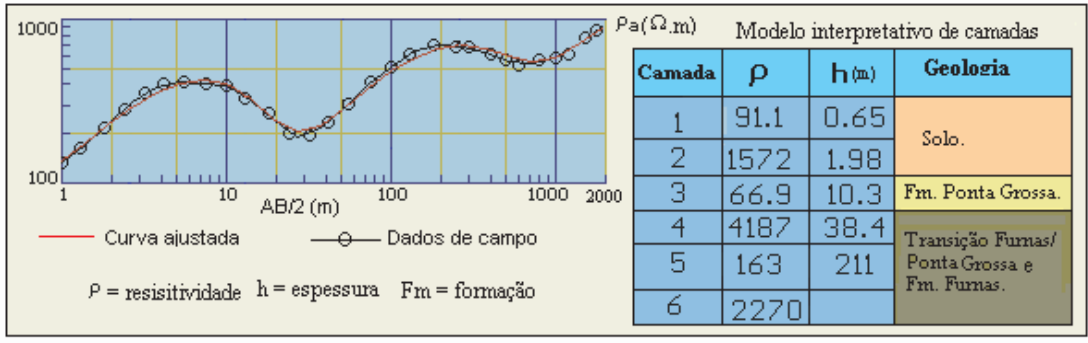

Figura 11 - Perfil geoelétrico da SEV6 e modelo interpretativo.

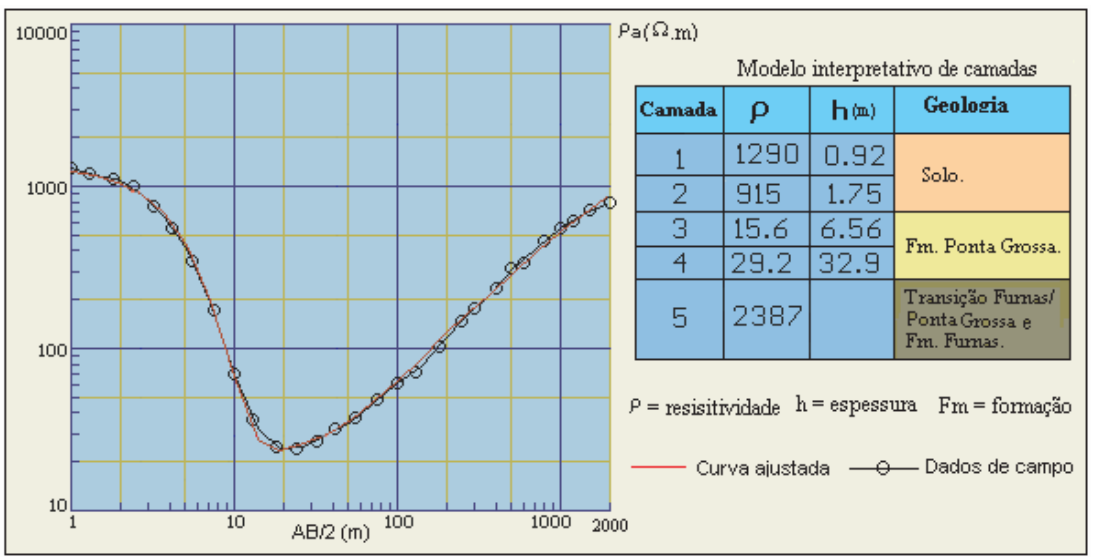

Figura 12 - Perfil geoelétrico da SEV7 e modelo interpretativo.

As SEVs com abertura de $\mathrm{AB} / 2$ superior a 1000 m mostram possíveis variações litológicas da Formação Furnas.

A utilização da espessura das unidades geológicas dos perfis de poços para auxiliar na interpretação das SEVs permitiu maior confiabilidade nos resultados obtidos.

Esta pesquisa produziu dados importantes para elaboração de modelo hidrogeológico conceitual, estimativa de reservas e avaliação de vulnerabilidade à contaminação do aqüífero Furnas na área, além de contribuir grandemente para a elaboração de projeto de poços tubulares.

\section{AGRADECIMENTOS}

A FAPEMAT (Fundação de Apoio a Pesquisa do Estado de Mato Grosso) pelo financiamento da pesquisa.

\section{REFERÊNCIAS}

ANDERSON MP \& WOESSNER WW. 1992. Applied groundwater modeling: simulation of flow and advective transport. Academic Press, New York, $381 \mathrm{p}$.

BHATTACHARYA PK \& PATRA HP. 1986. Direct Current Geoelectric Sounding. Elsevier Publishing Company, New York, 134 p. 
Tabela 1 - Espessuras e profundidades das unidades geológicas estimadas através das SEVs.

\begin{tabular}{|c|c|c|c|c|c|c|c|c|c|c|c|c|c|c|}
\hline \multirow[t]{2}{*}{ Geologia } & \multicolumn{2}{|c|}{ SEV1 } & \multicolumn{2}{|c|}{ SEV2 } & \multicolumn{2}{|c|}{ SEV3 } & \multicolumn{2}{|c|}{ SEV4 } & \multicolumn{2}{|c|}{ SEV5 } & \multicolumn{2}{|c|}{ SEV6 } & \multicolumn{2}{|c|}{ SEV7 } \\
\hline & $\mathrm{h}$ & $d$ & $\mathrm{~h}$ & $d$ & $\mathrm{~h}$ & $d$ & $\mathrm{~h}$ & $d$ & $\mathrm{~h}$ & $d$ & $\mathrm{~h}$ & $d$ & $\mathrm{~h}$ & $d$ \\
\hline Solo & 5 & 0 & 4 & 0 & 3 & 0 & 3 & 0 & 3 & 0 & 3 & 0 & 3 & 0 \\
\hline Fm. Ponta Grossa & 40 & 5 & 63 & 4 & 21 & 3 & 14 & 3 & 32 & 3 & 10 & 3 & 39 & 3 \\
\hline $\begin{array}{l}\text { T. Furnas Ponta/ } \\
\text { Grossa e Fm. } \\
\text { Furnas }\end{array}$ & $>700$ & 45 & $>700$ & 67 & $>250$ & 24 & $>300$ & 17 & $>700$ & 35 & $>700$ & 13 & $>700$ & 42 \\
\hline
\end{tabular}

$F m=$ Formação, $T$ = transição, $h=$ espessura $(m), d=$ profundidade $(m)$.

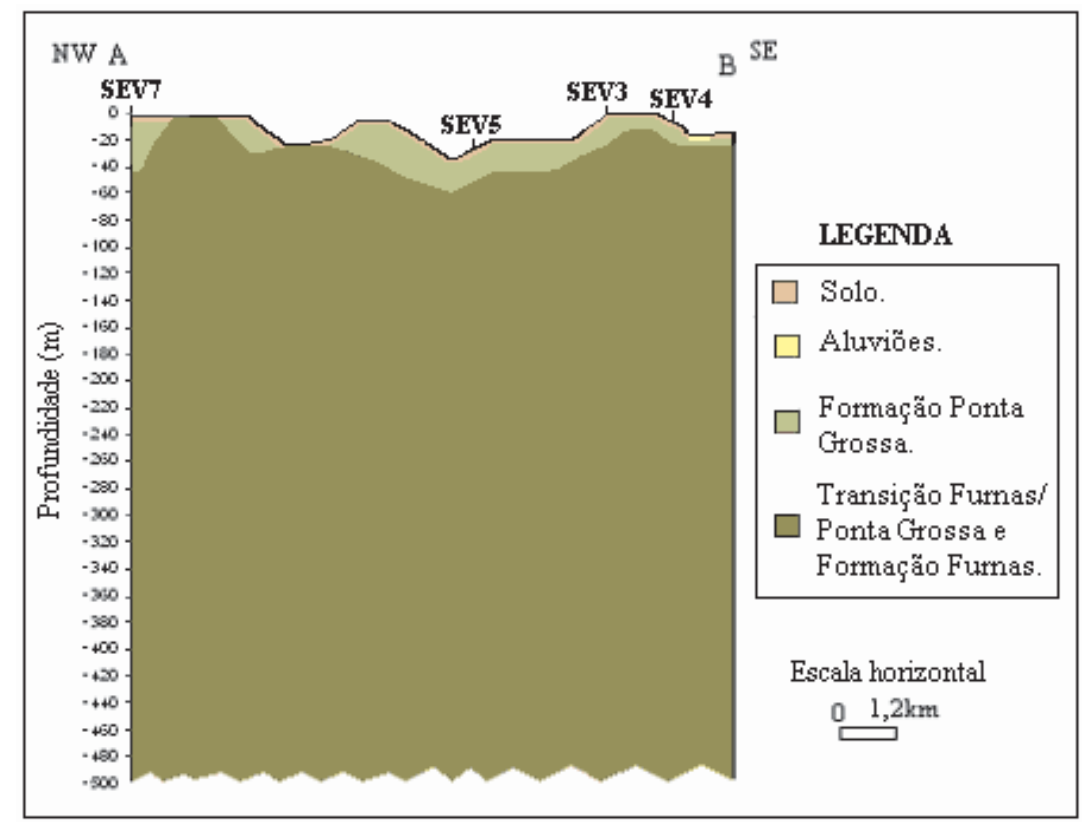

Figura 13 - Perfil geológico esquemático construído com base nas SEVs 3, 4, 5 e 7, no mapa geológico e em dados de poços tubulares.

COSTA WD. 2000. Uso e gestão de água subterrânea. In: Hidrogeologia conceitos e aplicações. CPRM Serviço Geológico Nacional, 341-365.

CUTRIM AO \& REBOUÇAS AC. (inédito a). Estudo da Vulnerabilidade e Risco à Contaminação do Aqüífero Furnas na Cidade de RondonópolisMT, Usando os Métodos DRASTIC e POSH.

CUTRIM AO \& REBOUÇAS AC. (inédito b). Uso integrado de águas subterrâneas e superficiais no abastecimento de água da cidade de Rondonópolis-MT.

CUTRIM AO \& REBOUÇAS AC. (inédito c). Caracterização hidrogeológica da Bacia do Paraná na Cidade de Rondonópolis-MT.

CUTRIM AO \& REBOUÇAS AC. 2005. Estimativa das reservas de água do Aqüífero Furnas na cidade de Rondonópolis-MT. $1^{0}$ Simpósio de Recursos Hídricos do Sul e $1^{0}$ Simpósio de Águas da AUGM. Santa Maria-RS, CD-ROM.
CUTRIM AO, SHOZO S \& NASCIMENTO AL. 2001. Contribuição da sondagem elétrica vertical à hidrogeologia da Bacia do Paraná no município de Juscimeira-MT. $7^{0}$ Congresso Internacional da Sociedade Brasileira de Geofísica, Salvador-BA, CD-ROM.

CUTRIM AO, SHOZO S, CASARIN JC \& REBOUÇAS ACR. 2002. Locação de poços tubulares profundos na Bacia do Paraná, no município de Rondonópolis - MT, usando sondagem elétrica vertical. XII Congresso Brasileiro de Águas Subterrâneas. Florianópolis-SC, CD-ROM.

CUTRIM AO \& FACHIN S-Jr. S. 2004. Aplicação integrada de sondagem elétrica vertical e perfil geológico de poço na determinação da profundidade e da espessura de unidades hidrogeológicas da Bacia do Paraná no município de Poxoréo-MT. XIII Congresso Brasileiro de Águas Subterrâneas. Cuiabá-MT, CD-ROM.

FOSTER S, HIRATA R, GOMES D, D'ELIA M \& PARIS M. 2002. Groundwater quality protection: a guide for water service companies, 
municipal authorities and environment agencies. World Bank, GWMATE. Washington, $101 \mathrm{p}$.

REBOUÇAS AC. 1976. Recursos hídricos subterrâneos da Bacia do Paraná. São Paulo, 143 p. Tese (Livre - Docência) - Instituto de Geociências, Universidade de São Paulo.
RUIZ AS, CUTRIM AO, CASARIN JC, VECCHIATO AB \& SALOMÃO FXT. (inédito). Mapeamento geológico da Bacia do Paraná na cidade de Rondonópolis-MT.

TIKHONOV AN \& ARSENIN VY. 1977. Solutions of ill-posed problems. Winston \& Sons, New York, 349 p.

\section{NOTAS SOBRE OS AUTORES}

Alterêdo Oliveira Cutrim. Graduado em matemática pela Universidade Federal do Maranhão em 1980. Mestrado em Geofísica pelo Centro de Geociências da UFPA em 1985. Doutorando em Hidrogeologia no IGc/USP. Professor Adjunto do Departamento de Geologia Geral da Universidade Federal de Mato Grosso, com atuação em Hidrogeologia e Geofísica Aplicada à Hidrogeologia.

Aldo da Cunha Rebouças. Graduado em Geólogo pela Escola de Geologia, Recife/CAGE em 1962. Mestrado em Hidrogeologia pela Université Strasbourg, França em 1964. Doutorado em Hidrogeologia pela Université Strasbourg, France em 1973. Pós-Doutorado em Stanford University, Califórnia, USA em 1986. Livre-Docência no IGc/USP em 1976. Professor de Hidrogeologia IGc/USP (aposentado). Colaborador da Pos-Graduação IGc/USP. Pesquisador do Instituto Estudos Avançados da USP desde 1996. 90 trabalhos publicados 35 internacionais (livros UNESCO, Brasil). Hidrogeólogo da SUDENE: 1964-1967. Hidrogeólogo Grupo Estudo Vale Jaguaribe:GEVJ/SUDENE/COOP. TEC. FRANCESA: 1963-1967. Coordenador Inventário Hidrogeológico Básico NE: 1967-1971. Consultor nacional e internacional desde, 1971. Atuação: Hidrogeologia e Gestão de Recursos Hídricos. 